Review Article

\title{
A Comparative Study of Over-Current Sensing for Traction Inverters
}

\author{
He Niu \\ American Axle \& Manufacturing, Detroit, MI, USA \\ Correspondence should be addressed to He Niu; he.niu@aam.com
}

Received 9 December 2020; Revised 28 December 2020; Accepted 8 January 2021; Published 21 January 2021

Academic Editor: Yuh-Shyan Hwang

Copyright (c) $2021 \mathrm{He}$ Niu. This is an open access article distributed under the Creative Commons Attribution License, which permits unrestricted use, distribution, and reproduction in any medium, provided the original work is properly cited.

\begin{abstract}
The over-current condition for a traction inverter can indicate flaws on control algorithms, interference on logic signals, hardware aging, or hardware misconduct. Thus, proper detection of over-current conditions during inverter operation is a critical item for inverter development and product validation. This paper reviews several widely used over-current detection methods and a few theoretically approved over-current detection methods. The main focus of this review includes the sensing bandwidth, sensing accuracy, and implementation complexity of the studied over-current detection methods. The advantages of those widely used methods and the application requirements for the theoretically and prototypingly approved methods are concluded by this review.
\end{abstract}

\section{Introduction}

In industrial applications and automotive applications, traction inverters are commonly used to convert DC input to AC output. The operating condition of a traction inverter can affect the power conversion output characteristics, the DC input's performance, and the inverter's self-reliability. Current and temperature are two of the critical metrics for inverter operation reliability. Inverter components such as power semiconductor and DC link capacitors are designed to operate within a safe current range and temperature range. Out-of-range inverter operation can result in poor inverter efficiency, quick aging of the inverter components, and permanent damage on critical inverter components [1]. Generally, critical components' temperature and current capability are cross-coupled. Thus, the inverter over-current detection sometimes can induce the consideration of inverter operating temperature [2].

State-of-the-art reviews on traction inverter current sensing have categorized existing methods based on sensing locations, monitoring signals, and complexity of hardware/ software implementation [3, 4]. Separate discussions for traction inverter open-circuit faults and short-circuit faults clarify the application of traction inverter current sensing on the two major inverter operation faults [4]. The short-circuit fault can result in a sudden current increase in the traction inverter, and the study in [4] falls into the category of this review. The temperature sensing on inverter's critical components, for instance, switching power semiconductor, can sometimes include current sensing. The temperaturecurrent look-up tables in [5] indicate that, in some applications, accurate current sensing, especially at high current conditions, is a factor for accurate temperature sensing.

Under fault-free operations, over-current detections usually require high sensing accuracy since a small percentage of current change at high current or marginal overcurrent operation can induce large inverter loss change $[6,7]$. Switching power semiconductors' tolerable shortcircuit time is usually several microseconds under a shortcircuit fault condition. As a result, the sensing bandwidth or response time for inverter over-current detections is critical. Another critical metric to evaluate inverter over-current detection methods is implementation complexity. In applications like electric vehicles, compact and low-cost design for traction inverter is widely accepted. Thus, a detection method with simple implementation can be more competitive over those complex methods.

This review discusses several widely used over-current detection methods for traction inverters. Based on the discussion on sensing bandwidth, sensing accuracy, and 
implementation complexity, the advantages of those widely used over-current detection methods are provided. Potential commercialization requirements for those theoretical and prototypingly approved methods are concluded by this review.

\section{Over-Current Locations in a Traction Inverter}

The three-phase output over-current of a traction inverter occurs on the three-phase connections between the traction inverter and the three-phase load. It is common to sense an inverter's three-phase output current at the location as marked in red in Figure 1. Current sensors are commonly set up at this location for phase current sensing. Under faultfree inverter operations, this can also be a location for inverter output over-current detection. Note that an inverter's three-phase output current can also be sensed at other locations as the following discussed.

The red locations in Figure 2 show the locations for inverter high-low side short-circuit detection. The inverter high-low side short circuit is a faulty operating condition and can induce a very high current in a short period of time. To protect the switching power semiconductor from overcurrent failure, the response time of this over-current condition should be less than the maximum allowable shortcircuit time of the switching power semiconductors.

Under a fault-free operating condition, the locations in Figure 2 can also be used for three-phase output overcurrent detection.

The red locations in Figure 3 shows the locations for inverter DC link short-circuit detection. Similar to the inverter high-low side short circuit, the DC link short-circuit is another faulty operation and can induce a very high current in a short period of time. Thus, a fast response time is required for over-current detection at this location. Note that the DC link short-circuit detections are not necessarily set up inside the inverter. Setting up the DC link short-circuit detection in the DC power source (a power battery, a DC power supply, etc.) is an alternative.

The earth ground or the housing of the traction inverter is usually configured so it has the same voltage as the DC link voltage's midpoint or the low point. An inverter hotlineto-earth ground short, as shown in Figure 4, can also induce a very high current in a short period of time. The detection of this over-current condition is usually a combination overcurrent detection at locations as shown in Figures 1-3.

\section{Over-Current Detection Methods}

3.1. Magnetic Field-Based Over-Current Detection. The magnetic field-based current sensing utilizes the circulating magnetic field generated by the phase current in a busbar. As shown in Figure 5, a C-shape ferrite core (colored with light blue) is used to constrain the generated magnetic field, and a hall-effect field detector (colored with red) is used to measure the field density. With a proper design of the shape of the ferrite core, the field density in the airgap of the C-shape ferrite core can be to-scale of the busbar current [8].

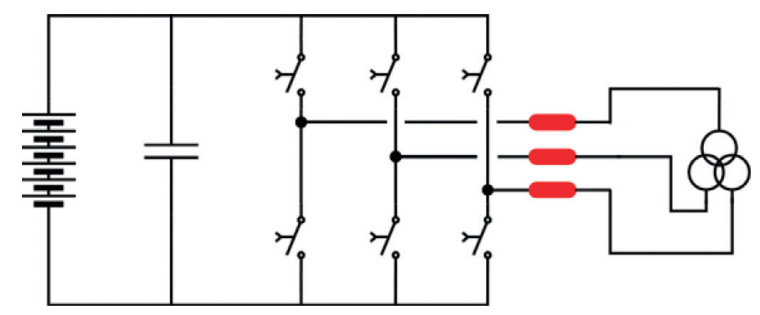

FIgURE 1: Traction inverter's three-phase output current sensing location.

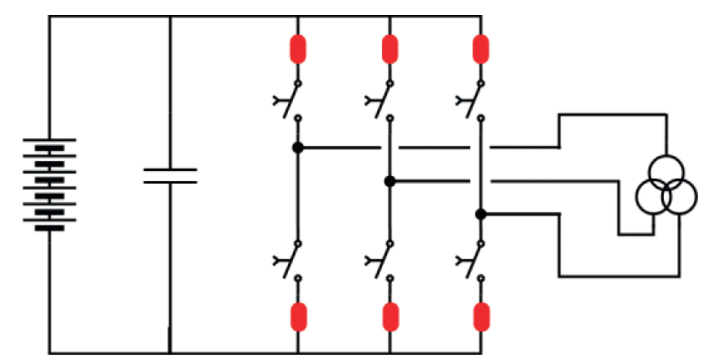

FIgURE 2: Traction inverter's high-low side short-circuit detecting location.

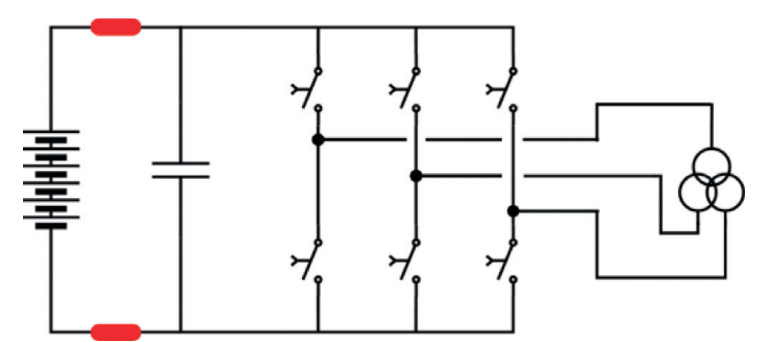

FIgURE 3: Traction inverter's DC link short-circuit detecting location.

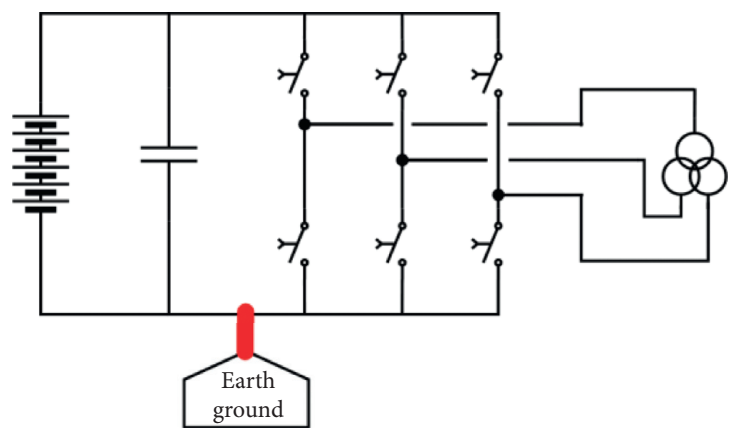

FIgURE 4: Traction inverter's hotline-to-earth ground short circuit.

Note that in some applications, the C-shape ferrite core can be replaced with a U-shape shield [9]. With proper field decoupling solutions, less than $1 \%$ sensing error can be achieved without using any magnetic field constrains (a U-core or a C-shield) [10].

The magnetic field-based current sensing methods are commonly used for traction inverter phase current sensing as shown in Figure 6. Generally, the sensing range of the 


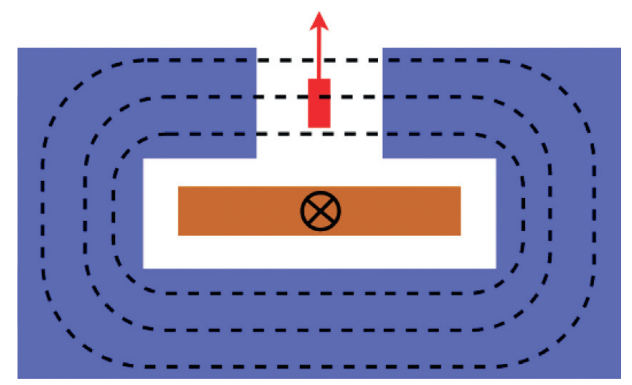

Figure 5: Magnetic field-based current sensing.

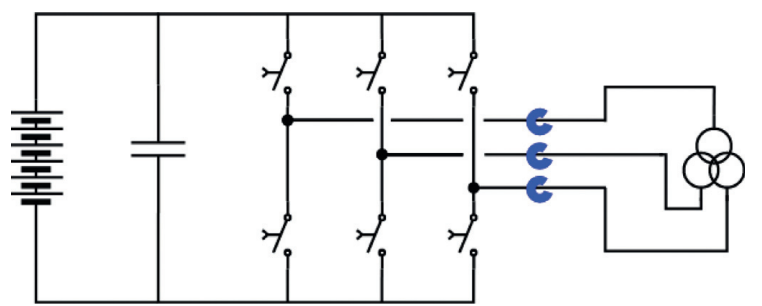

FIgURE 6: Traction inverter phase current sensing with the magnetic field-based sensors.

phase current sensor will be set to 1.3 to 1.5 times the full load current so the redundancy can be used for over-current detection. As afore-discussed, as long as the magnetic field constrains are not saturated, the over-current detection can be as accurate as the in-range phase current sensing.

The over-current response time of a hall-effect field detector output can be several microseconds [11]. However, due to the switching noise on the inverter output phase, RCtype filters are commonly used on the outputs of the inverter phase current sensor [12]. Thus, the response time can be further reduced.

The magnetic field-based current sensors do not have a galvanic connection to the phase-current busbar. As a result, no signal isolation is required and the hall-effect field detector can share the same power supply with the inverter's microcontroller. If any magnetic field constraints (such as a $\mathrm{C}$-shape core or a U-shape shield) are used, the current sensor can be bulky.

3.2. Shunt Resistor-Based Over-Current Detection. The shunt resistor-based current sensing detects the voltage drop across a resistor and estimates the current through the resistor based on $i=V / R$. In a traction inverter application, a common design for a shunt resistor is a small piece of alloy with a very low resistance-temperature dependency and the sensing accuracy can achieve less $1 \%$ error [13]. Because the measurement of the voltage drop across the shunt requires a galvanic connection to the busbar, an isolation circuitry can be required between the current sensor and the microcontroller, as shown in Figure 7. Similar to the magnetic field-based current sensing, if a shunt is used for traction inverter phase current sensing as shown in Figure 8, the sensing range can be set up-to 1.3 to 1.5 times the full load

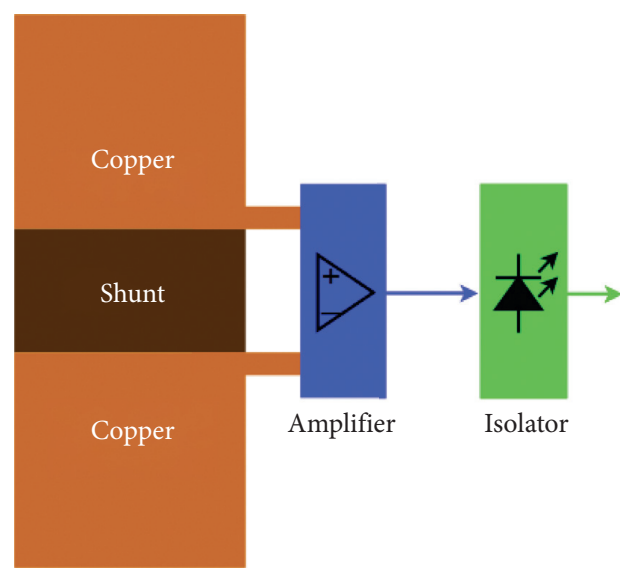

Figure 7: A shunt resistor-based current sensor with amplifer and isolator.

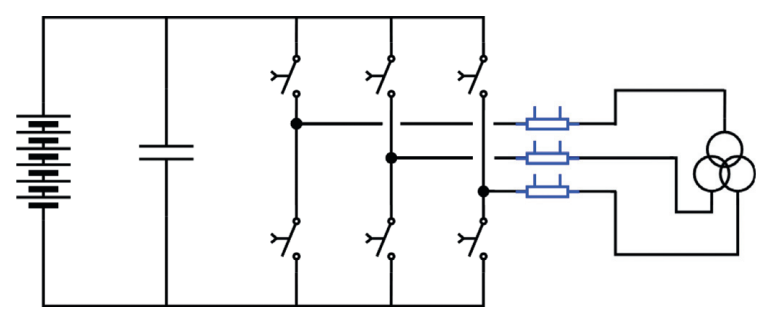

FIgURE 8: Traction inverter phase current sensing with the shunt resistor-based current sensors.

current so the redundancy can be used for over-current detection.

If an isolation circuitry is used, the shunt resistor-based over-current detection's response time will mostly rely on the response time of the isolation circuitry. Some commercialized solutions can provide an up-to several nanoseconds response time [14].

If shunt resistors are set up at the location as shown in Figure 2, the over-current detection circuitry can share the same power supply with the gate drive. The benefit of having the over-current detection circuitry and the gate drive to share the same power supply is that the over-current feedback can directly regulate the gate drive without signal isolation. Regan at al. [15] has proposed various of shunt resistor-based over-current detection solutions. A typical solution is shown in Figure 9. Because of the usage of the filtering capacitor $C_{\text {filt, }}$, the response time can be several nanoseconds to several microseconds.

3.3. Detection on a Power Semiconductor. When a power MOSFET or an IGBT is on, the device's on-state voltage drop will increase with the forward current. Thus, the on-state voltage drop of switching power semiconductor can be used for over-current detection. Considering that the power semiconductor's "on-state voltage-to-forward current" relationship is temperature-sensitive, this method may not meet the accuracy for current regulation. Usually, this method is used for high-low side short-circuit detection as afore-discussed with Figure 2. When a high-low side short- 


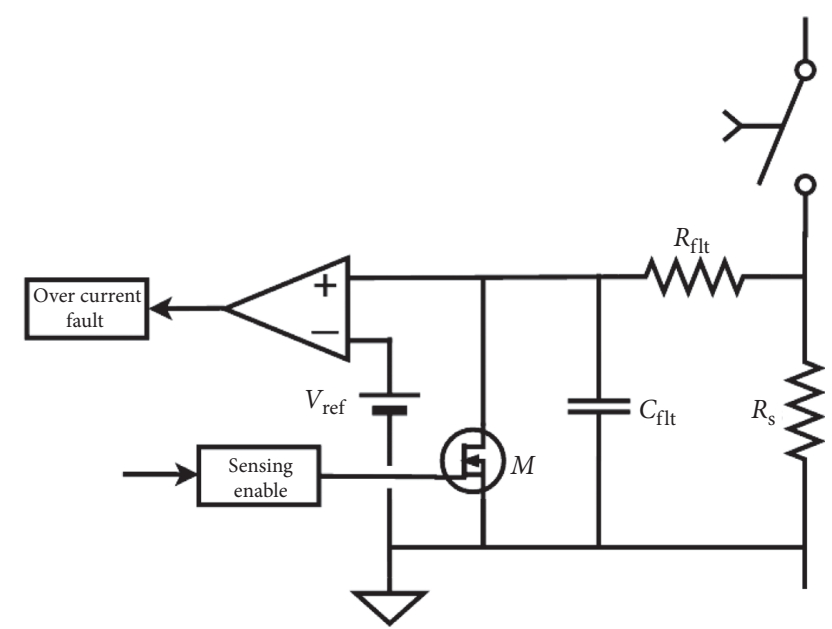

FIgURE 9: Shunt resistor-based over-current detection.

circuit occurs, a very large on-state current will pull the device into saturation. By detecting on-state voltage drop and turn off the power semiconductor switch before the device saturates, a high-low side short-circuit faulty operation can be stopped. This type of over-current detection is also named as desaturation protection.

In [16], two typical over-current detection solutions are proposed based on desaturation circuit, as shown in Figures 10 and 11. In the case of Figure 10, a high over-current will generate a large on-state voltage across the power switch. The voltage across $C_{\mathrm{blk}}$ will track the on-state voltage and eventually trigger the over-current protection. The response time of the over-current detection mostly depends on the output rating of the constant current source $I_{c}$ and $C_{\mathrm{blk}}$. Due to the high switching noise across the power switch, $C_{\mathrm{blk}}$ is required and it results in tens of nanoseconds to several microseconds' delay. Some switching power semiconductor has an internal current sensing output as shown in Figure 12. The afore-discussed desaturation circuit can also be used for over-current detection.

The benefit of using the desaturation circuit is that the sensing circuitry can share the same power supply with the gate drive. In [16], a gate drive solution that integrates the desaturation circuit into the gate drive IC is provided.

3.4. Detection with the Power Semiconductor Gate Drive Circuitry. The interaction between the gate drive and the switching power semiconductor during the switching transient can be correlated to the device current and device junction temperature [17]. If the effect of junction temperature is mild or can be decoupled, the gate drive switching performance can be used for switching power semiconductor over-current detection. Generally, overcurrent detection using gate drive switching performance is used at locations as shown in Figure 2. Niu and Lorenz [18] proposed a method to use gate drive output current for overcurrent detection as shown in Figure 13. In [19-22], several over-current detection methods based on gate drive output voltage are proposed. The methods using gate drive switching performance generally require signal processing to correlate the measurement to the power device's current.

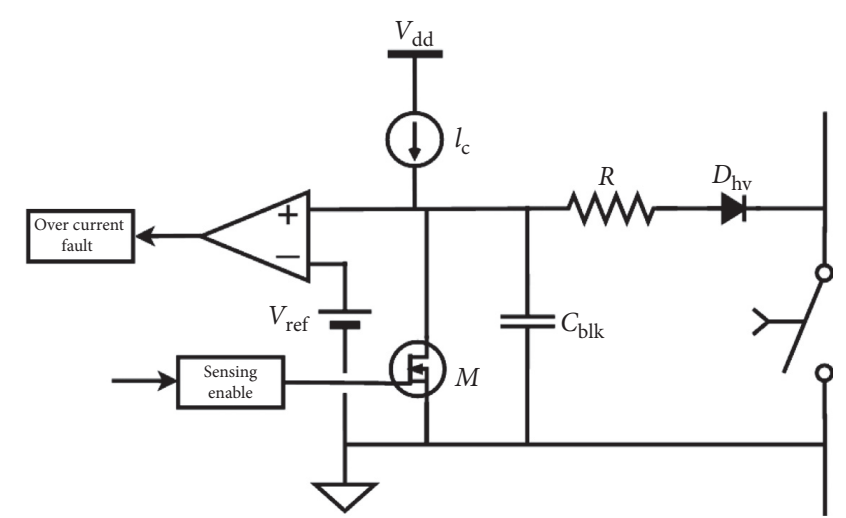

FIGURE 10: A desaturation circuit using constant current source.

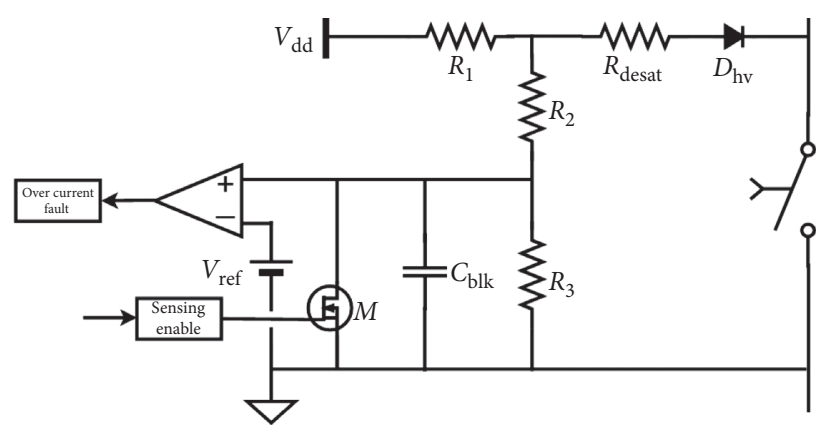

Figure 11: A desaturation circuit using voltage divider.

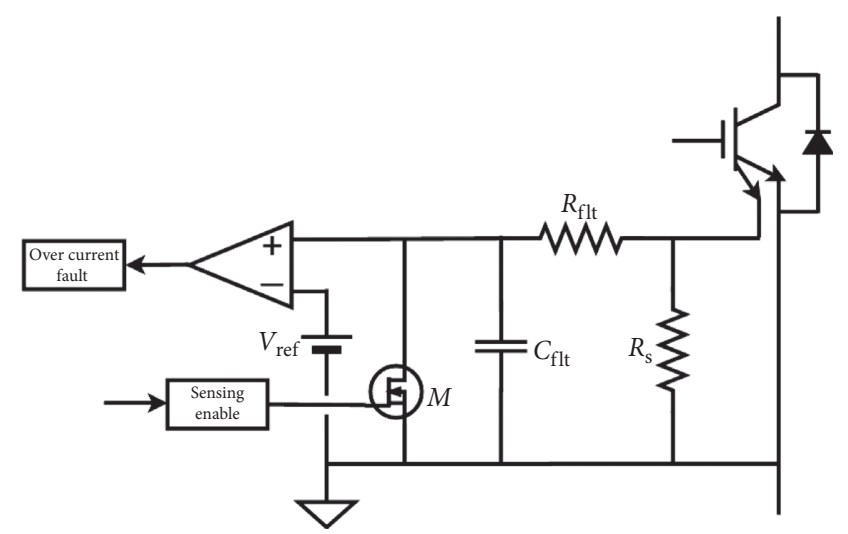

FIGURE 12: Over-current detection using IGBT internal current sensor.

Because of the temperature dependency and the power semiconductor part-to-part variation, most of the gate drivebased over-current detection cannot achieve very high accuracy. For those methods based on the gate drive switching transient, every current measurement is achieved right after the switching transient. If a short-circuit occurs at the middle of a conduction cycle, over-current can only be detected after the next switching transient.

\section{Hardware and Software Implementations}

The applications of the afore-discussed methods on different over-current detecting locations are summarized in Table 1. 


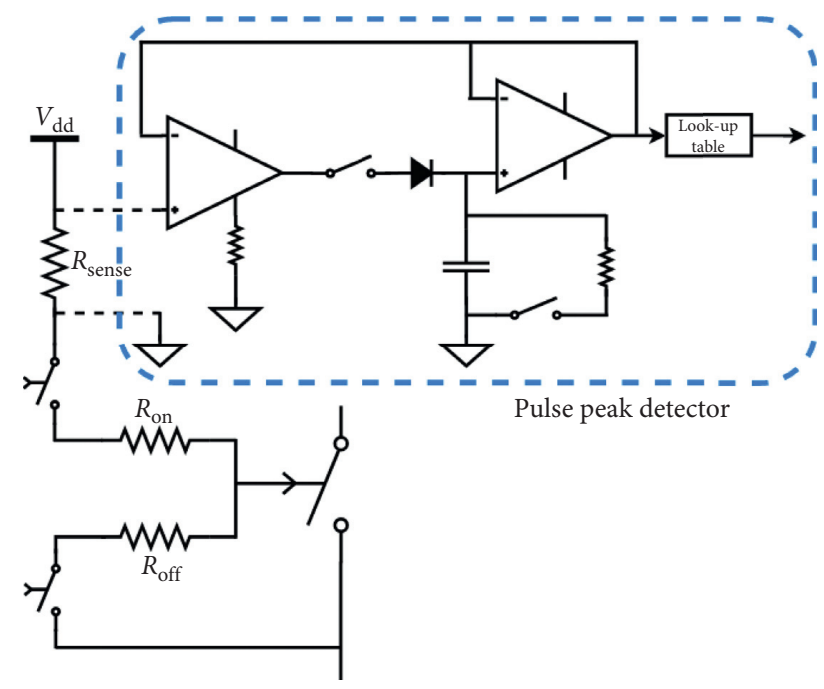

FIGURE 13: Over-current detection using gate drive output current pulse peak.

TABLE 1: Over-current detecting locations.

\begin{tabular}{lccc}
\hline & $\begin{array}{c}\text { Inverter } \\
\text { 3-phase } \\
\text { over- } \\
\text { current }\end{array}$ & $\begin{array}{c}\text { Inverter } \\
\text { high-low side } \\
\text { short-circuit }\end{array}$ & $\begin{array}{c}\text { Inverter DC } \\
\text { link short- } \\
\text { circuit }\end{array}$ \\
\hline $\begin{array}{l}\text { Magnetic field-based } \\
\text { Shunt resistor-based }\end{array}$ & $\begin{array}{c}\text { Suitable } \\
\text { Suitable }\end{array}$ & $\begin{array}{c}\text { Can be bulky } \\
\text { Suitable }\end{array}$ & $\begin{array}{c}\text { Suitable } \\
\text { Suitable }\end{array}$ \\
$\begin{array}{l}\text { Detection on power } \\
\text { semiconductor }\end{array}$ & & Suitable & \\
$\begin{array}{l}\text { Detection with gate } \\
\text { drive }\end{array}$ & & Suitable & \\
\hline
\end{tabular}

The magnetic field-based current sensing methods and the shunt resistor-based current sensing methods can be applied to all three over-current detecting locations. For the overcurrent detecting methods based on "detection on power semiconductor" and "detection with gate drive," the most suitable applications will be the inverter high-low side shortcircuit detection.

The power supply solutions for the afore-discussed overcurrent detection methods are summarized in Table 2. The magnetic field-based over-current detection circuitry is galvanic isolated to the conductor. Thus, it can share a power supply with the inverter controller and directly communicate with the controller. The shunt resistor-based overcurrent detection circuitry will directly connect to the high current conductor, and it is suitable to have an independent isolated power supply. For the over-current detecting methods based on "detection on power semiconductor" and "detection with gate drive," since the detecting components (the power semiconductor or the gate drive) is directly driven by the gate drive power supply, it is suitable to have the detecting circuitry to share the same power supply with the gate drive.

For the "magnetic field-based methods," "shunt resistorbased methods," and the "methods based on detection on power semiconductor," the measurement can be directly compared to a threshold to validate the over-current
TABLE 2: Power supply solutions for the over-current detection methods.

\begin{tabular}{|c|c|c|c|}
\hline & $\begin{array}{c}\text { Inverter } \\
\text { controller } \\
\text { power supply }\end{array}$ & $\begin{array}{c}\text { Gate drive } \\
\text { power } \\
\text { supply }\end{array}$ & $\begin{array}{c}\text { Independent } \\
\text { isolated } \\
\text { power supply }\end{array}$ \\
\hline Magnetic field-based & Suitable & Feasible & Feasible \\
\hline Shunt resistor-based & & Feasible & Suitable \\
\hline $\begin{array}{l}\text { Detection on power } \\
\text { semiconductor }\end{array}$ & & Suitable & \\
\hline $\begin{array}{l}\text { Detection with gate } \\
\text { drive }\end{array}$ & & Suitable & \\
\hline
\end{tabular}

TABLE 3: Signal processing requirements for the over-current detection methods.

\begin{tabular}{lccc}
\hline & $\begin{array}{c}\text { Direct } \\
\text { detection }\end{array}$ & $\begin{array}{c}\text { Simple } \\
\text { circuitry } \\
\text { processing }\end{array}$ & $\begin{array}{c}\text { Complex } \\
\text { signal processing }\end{array}$ \\
\hline $\begin{array}{l}\text { Magnetic field-based } \\
\text { Shunt resistor-based }\end{array}$ & Yes & & \\
$\begin{array}{l}\text { Petection on power } \\
\text { semiconductor }\end{array}$ & Yes & & \\
$\begin{array}{l}\text { Detection with gate } \\
\text { drive }\end{array}$ & & $\begin{array}{c}\text { Sometimes } \\
\text { feasible }\end{array}$ & Yes \\
\hline
\end{tabular}

condition. The methods based on "detection with gate drive" can require complex signal processing such as peak detection, integration, high-resolution time count, and so forth. As a result, hardware/software implementation can be expensive. The aforementioned signal processing requirements are summarized in Table 3.

This paper has covered the discussion for over-current sensing response time. The response time for the aforementioned over-current sensing methods can be caseby-case due to the selection of filtering circuity and sampling frequency. Instead of directly providing a response time comparison, a comparison of dominant sensing response time contributors is listed as shown in Table 4. Generally, the "magnetic field-based methods" and the "methods based on detection on power semiconductor" have the dominant sensing response time contribution from RC filter-induced delay because of the switching transient induced noise. The "shunt resistor-based methods" are more dominated by the isolation delay. For the methods based on "detection with gate drive," over-current detection only occurs at the switching transient. Thus, the largest possible sensing response time is the time period between two switching transient actions.

\section{Conclusions}

This paper reviews several widely used over-current detection methods and a few theoretically approved over-current detection methods. The application and the popularity of the discussed over-current detection methods rely on their sensing accuracy, sensing bandwidth, and implementation complexity. Suitable over-current detecting locations, circuitry power supply selections, and requirements for signal processing are concluded. 
TABle 4: Dominant sensing response time contributors for the over-current detection methods.

\begin{tabular}{|c|c|c|c|}
\hline & $\begin{array}{c}\text { RC } \\
\text { filter-inducted } \\
\text { delay }\end{array}$ & $\begin{array}{c}\text { Isolation } \\
\text { delay }\end{array}$ & $\begin{array}{c}\text { Delay due to } \\
\text { sampling } \\
\text { frequency }\end{array}$ \\
\hline Magnetic field-based & Yes & & \\
\hline Shunt resistor-based & & Yes & \\
\hline $\begin{array}{l}\text { Detection on power } \\
\text { semiconductor }\end{array}$ & Yes & & \\
\hline $\begin{array}{l}\text { Detection with gate } \\
\text { drive }\end{array}$ & & & Yes \\
\hline
\end{tabular}

\section{Conflicts of Interest}

The authors declare that they have no conflicts of interest.

\section{References}

[1] D. Ward, Fundamentals of Semiconductors for Hybrid Electric Powertrain, Infineon Technology North America Corp., Livonia, MI, USA, 2013.

[2] H. Niu, "A review of power cycle driven fatigue, aging, and failure modes for semiconductor power modules," in Proceedings of the IEEE International Electric Machines and Drives Conference (IEMDC), Miami, FL, USA, May 2017.

[3] A. Lee and E. Robert, "Design issues for magnetic field-based current sensing in electric machine drive applications," in Proceedings of the IEEE International Conference on Electro/ Information Technology (EIT), Rochester, MI, USA, May 2018.

[4] A. Lee and E. Robert, "Current transducer delay for electric machine drives in aviatio," in Proceedings of the IEEE International Conference on Electro/Information Technology (EIT), Rochester, MI, USA, May 2018.

[5] H. Niu and R. D. Lorenz, "Real-time junction temperature sensing for silicon carbide MOSFET with different gate drive topologies and different operating conditions," IEEE Transactions on Power Electronics, vol. 33, no. 4, pp. 3424-3440, 2018.

[6] R. Pagano, Y. Chen, K. Smedley, S. Musumeci, and A. Raciti, "Shortcircuit analysis and protection of power module IGBTs," in Proceedings of the IEEE Twentieth Annual IEEE Applied Power Electronics Conference and Exposition, 2005, pp. 777-783, Austin, TX, USA, March 2005.

[7] R. Pagano and A. Raciti, "Evolution in IGBT's protection against shortcircuit behaviors by gate-side circuitry," in Proceedings of the 2002 IEEE International Symposium on Industrial Electronics, 2002. ISIE 2002, pp. 913-918, L'Ayuila, Italy, July 2002.

[8] M. Sheng, H. Nogawa, M. Alvi, and R. Lorenz, "Current sensing integration with lead frames in 6-in-1 IGBT modules," in Proceedings of the 2018 IEEE Energy Conversion Congress and Exposition (ECCE), Portland, OR, USA, September 2018.

[9] M. Sheng, M. Alvi, and R. Lorenz, "GaN PCB integrated sensing system for switch and capacitor currents," in Proceedings of the 2019 IEEE Applied Power Electronics Conference and Exposition (APEC), Anaheim, CA, USA, March 2019.

[10] M. Sheng, M. Alvi, and R. Lorenz, "GMR-based integrated current sensing in $\mathrm{SiC}$ power modules with phase shift error reduction," IEEE Journal of Emerging and Selected Topics in Power Electronics, In press.

[11] MLX91208 IMC-Hall Current Sensor, Melexis Co. Ltd., 2020, https://www.melexis.com/en/product/MLX91208/ 250kHz-Programmable-IMC-Hall-Current-Sensor.
[12] M. Nari, "A dual-shielding method for magnetic field-based current sensing," in Proceedings of the 2018 IEEE Energy Conversion Congress and Exposition (ECCE), Portland, OR, USA, September 2018.

[13] S. Ziegler, R. C. Woodward, H. H.-C. Iu, and L. J. Borle, "Current sensing techniques: a review," IEEE Sensors Journal, vol. 9, no. 4, pp. 354-376, 2009.

[14] Simplifying Current Sensing-How to Design with Current Sense Amplifiers, Texas Instruments, Dellas, TX, USA, 2020, https://www.ti.com/amplifier-circuit/current-sense/ support-training.html.

[15] T. Regan, J. Munson, G. Zimmer, and M. Stokowski, "Current sense circuit collection-making sense of current," Linear Technology, 2005. https://www.analog.com/media/en/technicaldocumentation/application-notes/an105fa.pdf.

[16] UCC2175010-A Source/Sink Reinforced Isolated Single Channel Gate Driver for SiC/IGBT with Active Protection, Isolated Analog Sensing and High-CMT, Texas Instruments, Dellas, TX, USA, 2019, https://www.ti.com/product/ UCC21750.

[17] H. Niu and R. D. Lorenz, "Evaluating different implementations of online junction temperature sensing for switching power semiconductor," IEEE Transactions on Industry Applications, vol. 53, no. 1, pp. 391-401, 2017.

[18] H. Niu and R. D. Lorenz, "Sensing power MOSFET junction temperature using gate drive turn-on current transient properties," IEEE Transactions on Industry Applications, vol. 52, no. 2, pp. 1677-1687, 2015.

[19] M. A. Rodriguez, A. Claudio, D. Theilliol, and L. G. Vela, “A new fault detection technique for IGBT based on gate voltage monitoring," in Proceedings of the IEEE Power Electronics Specialists Conference, pp. 1001-1005, Orlando, FL, USA, June 2007.

[20] S. Musumeci, R. Pagano, A. Raciti, G. Belverde, C. Guastella, and M. Melito, "A novel protection technique devoted to the improvement of the short circuit ruggedness of IGBTs," in Proceedings of the IECON'03. 29th Annual Conference of the IEEE Industrial Electronics Society (IEEE Cat. No.03CH37468), pp. 1733-1738, Roanoke, VA, USA, November 2003.

[21] R. S. Chokhawala and S. Sobhani, "Switching voltage transient protection schemes for high-current IGBT modules," IEEE Transactions on Industry Applications, vol. 33, no. 6, pp. 1601-1610, 1997.

[22] A. Bhalla, S. Shekhawat, J. Gladish, J. Yedinak, and G. Dolny, "IGBT behavior during desat detection and short circuit fault protection," in Proceedings of the 10th International Symposium on Power Semiconductor Devices and ICs. ISPSD'98 (IEEE Cat. No.98CH36212), pp. 245-248, Kyoto, Japan, June 1998. 